\title{
Polymorphisms in $A H I 1$ are not associated with type 2 diabetes or related phenotypes in Danes: non-replication of a genome-wide association result
}

\author{
J. Holmkvist • S. Anthonsen • L. Wegner • \\ G. Andersen - T. Jørgensen • K. Borch-Johnsen • \\ A. Sandbak • T. Lauritzen • O. Pedersen • T. Hansen
}

Received: 15 October 2007 / Accepted: 14 December 2007 /Published online: 29 January 2008

(C) Springer-Verlag 2008

\begin{abstract}
Aims/hypothesis A genome-wide association study recently identified an association between common variants, rs1535435 and rs9494266, in the AHII gene and type 2 diabetes. The aim of the present study was to investigate the putative association between these polymorphisms and type 2 diabetes or type 2 diabetes-related metabolic traits in Danish individuals.

Methods The previously associated polymorphisms were genotyped in the population-based Inter99 cohort $(n=$ $6162)$, the Danish ADDITION study $(n=8428)$, a population-based sample of young healthy participants $(n=377)$ and in additional type 2 diabetes $(n=2107)$ and glucose-
\end{abstract}

Electronic supplementary material The online version of this article (doi:10.1007/s00125-008-0925-z) contains supplementary material, which is available to authorised users.

J. Holmkvist $(\bowtie) \cdot$ S. Anthonsen $\cdot$ L. Wegner $\cdot$ G. Andersen •

K. Borch-Johnsen $\cdot$ O. Pedersen $\cdot$ T. Hansen

Steno Diabetes Center,

Niels Steensens Vej 1, NLC2.12,

2820 Gentofte, Denmark

e-mail:chkv@steno.dk

T. Jørgensen $\cdot$ K. Borch-Johnsen

Research Centre for Prevention and Health,

Glostrup University Hospital,

Glostrup, Denmark

K. Borch-Johnsen $\cdot$ O. Pedersen

Faculty of Health Science, University of Aarhus,

Aarhus, Denmark

A. Sandbæk $\cdot$ T. Lauritzen

Department of General Practice, University of Aarhus,

Aarhus, Denmark tolerant participants $(n=483)$ using Taqman allelic discrimination. The case-control study involved 4,104 type 2 diabetic patients and 5,050 glucose-tolerant control participants. Type 2 diabetes-related traits were investigated in 17,521 individuals.

Results rs 1535435 and rs9494266 were not associated with type 2 diabetes. Odds ratios (OR) were $\mathrm{OR}_{\text {add }} 1.0$ (95\% C.I. $\left.0.9-1.2 ; p_{\text {add }}=0.7\right)$ and $\mathrm{OR}_{\text {add }} 1.1\left(0.9-1.2 ; p_{\text {add }}=0.4\right)$, respectively, a finding supported by meta-analyses: $\mathrm{OR}_{\mathrm{add}}$ $1.0\left(0.9-1.1 ; p_{\text {add }}=0.6\right)$ and $\mathrm{OR}_{\text {add }} 1.0\left(0.9-1.1 ; p_{\text {add }}=0.6\right)$, respectively. Neither rs 1535435 nor rs9494266 were consistently associated with any of the tested type 2 diabetesrelated metabolic traits.

Conclusions/interpretation Data from large samples of Danish individuals do not support a role for AHII rs1535435 nor rs9494266 as major type 2 diabetes variants. This study highlights the importance of independent and well-powered replication studies of the recent genome-wide association scans before a locus is robustly validated as being associated with type 2 diabetes.

Keywords AHI1 - Association · Chromosome 6 - Genetics . Single nucleotide polymorphism $\cdot$ SNP. Type 2 diabetes

$\begin{array}{ll}\text { Abbreviations } \\ \text { BIGTT } & \begin{array}{l}\text { beta cell function, insulin sensitivity, } \\ \text { glucose tolerance test }\end{array} \\ \text { DGI } & \begin{array}{l}\text { Diabetes Genetics Initiative } \\ \text { genome-wide association }\end{array} \\ \text { GWA } & \text { impaired fasting glycaemia } \\ \text { IFG } & \text { impaired glucose tolerance } \\ \text { IGT } & \text { odds ratio } \\ \text { OR } & \text { single nucleotide polymorphism } \\ \text { SNP } & \text { Wellcome Trust Case Control Collection }\end{array}$




\section{Introduction}

Type 2 diabetes is a common, multifactorial disease and a rapidly growing health problem affecting both morbidity and mortality. More than 180 million individuals are reported to suffer from type 2 diabetes with an estimated doubling within the next 15 years $[1,2]$. The multifactorial nature of diabetes has made the search for diabetes genes difficult, and only a few genes have rigorously been proven to play a role in type 2 diabetes. Recent technological advances have made genome-wide association (GWA) studies feasible [3, 4] and to date 12 GWA studies for type 2 diabetes have been published [5-16]. These studies have confirmed previously known type 2 diabetes genes (TCF7L2, PPARG and KCNJ11), but have also identified a number of new potential type 2 diabetes genes (CDKAL1, CDKN2A/CDKN2B locus, IGF2BP2, HHEX/ KIF11/IDE locus, SLC30A8 and FTO) [5-10]. Several of the top-ranked markers in these scans are found in unsuspected type 2 diabetes genes and in regions without annotated genes. Due to the massive number of performed analyses false positive results are expected [17], making replication of GWA data by independent researchers in independent cohorts warranted before a locus is convincingly associated with type 2 diabetes. Genome-wide significant association $\left(p<2.3 \times 10^{-7}\right)$ with type 2 diabetes was found in one of the recent GWAs for two polymorphisms (rs1535435 and rs9494266) in the AHII locus on chromosome $6 \mathrm{q} 23.3$ [11], in proximity of regions that have previously shown suggestive linkage to type 2 diabetes, impaired glucose homeostasis, age at onset of type 2 diabetes and both fasting insulin- and lipid concentrations [18-22]. The association with type 2 diabetes was found for the A-alleles of rs 1535435 and rs9494266 in 500 type 2 diabetic patients and 497 control persons originating from four different white populations [rs1535435 odds ratio (OR) $2.3\left(p=1 \times 10^{-5}\right)$ and rs9494266 OR $2.3\left(p=2 \times 10^{-5}\right)$ ]. These results were replicated in a large French sample (previously used for GWA replication purposes [7]) consisting of 2,573 type 2 diabetic patients and 2,776 control participants $[\mathrm{OR}=1.3$ $\left(p=2 \times 10^{-4}\right]$ and OR $1.3\left[p=5 \times 10^{-5}\right]$, respectively; French samples and previously mentioned GWA study [11] combined: $p=1 \times 10^{-6}$ and $p=2.3 \times 10^{-7}$ ).

Mutations in AHII have previously been shown to cause Joubert syndrome 3 [23], which is an autosomal recessive syndrome characterised by hypoplasia of cerebellar vermis and malformation of the brain stem. Variation in the AHII locus has also been associated with schizophrenia in Israeli-Arab families and in an Icelandic population [24-26]. The function of Abelson helper integration site 1 (AHI1), the protein encoded by $A H I 1$, is not known, but it contains multiple SH3 and WD40 domains [27], suggesting that it acts as a scaffolding protein or a docking site [28, 29].

The aim of this study was to validate the recent association with type 2 diabetes $(n=9154)$ and explore possible associations with metabolic traits related to type 2 diabetes in Danish individuals $(n=17,521)$.

\section{Methods}

Participants The two polymorphisms (rs1535435 and rs9494266) were genotyped in 17,521 Danish individuals. Participants from the population-based Inter99 cohort [30] involving 6162 individuals were characterised by an OGTT as having normal glucose tolerance $(n=4567)$, impaired fasting glycaemia (IFG; $n=508$ ), impaired glucose tolerance (IGT; $n=707)$ or screen-detected type 2 diabetes $(n=$ 256) and were investigated for an association between genotype and quantitative metabolic traits; 124 had known type 2 diabetes and were excluded prior to these analyses. An additional 377 individuals, recruited from a populationbased sample of young healthy Danish individuals at the Research Centre for Prevention and Health [31] and 8,428 individuals recruited from the ADDITION study sampled through the Department of General Practice at University of Aarhus [32] were enrolled to study quantitative metabolic traits. The case-control study included all unrelated type 2 diabetes patients and healthy glucose-tolerant control individuals from the Inter99 cohort (patients $n=380$, control individuals $n=4,567$ ) [30], the Danish ADDITION study (patients $n=1,617$; all screen-detected and untreated) [32] and individuals recruited from the outpatient clinic at Steno Diabetes Center (patients $n=2107$, control individuals $n=$ 483). Detailed description of the participants is given in Electronic supplementary material (ESM; ESM Supplementary characteristics and ESM Tables 1 and 2). In brief, impaired glucose homeostasis (IFG, IGT and diabetes) was defined according to WHO criteria after a 75 g OGTT [33]. All participants were of Danish nationality and had provided informed written consent before participation. The study was approved by the Ethical Committees of Copenhagen and Aarhus and was in accordance with the principles of the Helsinki Declaration II.

Biochemical and anthropometric measurements Height and body weight were measured in light indoor clothes and without shoes and BMI was calculated as weight $(\mathrm{kg})$ divided by height $(\mathrm{m})^{2}$. Waist circumference was measured in the standing position midway between the iliac crest and the lower costal margin and hip circumference at its maximum. In the Inter99 and Steno Diabetes Center 
participants, blood samples were drawn after a $12 \mathrm{~h}$ overnight fast. Plasma glucose was analysed by a glucose oxidase method (Granutest, Merck, Darmstadt, Germany); $\mathrm{HbA}_{1 \mathrm{c}}$ was measured by ion-exchange high performance liquid chromatography (normal reference range 4.1-6.4\%); and serum insulin, excluding $\operatorname{des}(31,32)$ proinsulin and intact proinsulin, was measured using the AutoDELFIA insulin kit (Perkin-Elmer/Wallac, Turku, Finland). In the 377 healthy participants, serum insulin was measured by ELISA using an insulin kit (Dako Diagnostics, Ely, UK) with overnight incubation. Serum C-peptide concentrations were measured by a time-resolved fluoroimmunoassay (AutoDELFIA C-peptide kit; Perkin-Elmer/Wallac). Serum triacylglycerol and total cholesterol and HDL-cholesterol were analysed using enzymatic colorimetric methods (GPO-PAP and CHOD-PAP; Roche Molecular Biochemicals, Mannheim, Germany). Insulin resistance was estimated according to the homeostasis model assessment index (www.dtu.ox.ac.uk/homa). BIGTT-insulin sensitivity index and BIGTT-acute insulin response, which use information on sex and BMI combined with analysis of plasma glucose and serum insulin levels at time points $0,30,120 \mathrm{~min}$ to provide indices for insulin sensitivity index $\left(S_{\mathrm{I}}\right)$ and acute insulin response (AIR) that highly correlate with indices obtained during an IVGTT, were calculated as described elsewhere [34]. Insulinogenic index ${ }_{30}$ min was calculated as fasting serum insulin subtracted from plasma insulin 30 min $(\mathrm{pmol} / \mathrm{l})$ divided by plasma glucose $_{30 \min }(\mathrm{mmol} / \mathrm{l})$.

Genotyping Genotyping was performed using Taqman allelic discrimination (Kbioscience, Hoddesdon, UK) with a success rate $>96.8 \%$. Discordance was $<0.1 \%$ as judged from re-genotyping of 1202 random duplicate samples.

Statistical analyses Fisher's exact test and logistic regression analyses were used to analyse differences in allele and genotype frequencies between patients and control persons; analyses were adjusted for age, BMI and sex. A general linear model was used to test quantitative variables for genotype differences between type 2 diabetes patients and healthy control participants, adjusting for age, sex, BMI and diabetes status ( 0 vs 1 variable) in analyses of the complete cohort. Meta-analyses of published data for the putative association between rs1535435 and rs9494266 and type 2 diabetes were performed using a Mantel-Haenszel test to estimate the combined OR of these studies. Power was calculated using the Genetic Power Calculator (http://pngu. mgh.harvard.edu/ purcell/gpc/) [35] where type 2 diabetes prevalence was estimated to $10 \%$ and with a relative risk of 1.15 (as described in the replication sample in the original article) [11]. The statistical analyses were performed using
RGui version 2.5.0 (available at www.r-project.org). The $p$ values were not adjusted for multiple testing.

\section{Results}

The rs1535435 and rs9494266 were genotyped in 17,521 Danish individuals and the potential association with type 2 diabetes was evaluated in 4,104 patients and 5,050 glucose-tolerant control individuals who had previously been used to replicate the associations between HHEX, $C D K N 2 A / B, I G F 2 B P 2, G C K R$ and type 2 diabetes [36]. Allele frequencies were in accordance with previously published results and in Hardy-Weinberg equilibrium ( $p>$ $0.05)$. Also, $D^{\prime}$ and $r^{2}$ values $\left(D^{\prime}=0.99 ; r^{2}=0.97\right)$ were in the same range as previously reported. Power to reject the null hypothesis was estimated to $\sim 85 \%$ assuming an additive model, risk allele frequency of $8.5 \%$ and a relative risk of 1.15 per allele.

The previously reported association between rs 1535435 and rs9494266 and type 2 diabetes was not confirmed in our case-control study, which generated the following ORs: $\mathrm{OR}_{\text {add }} 1.0\left(95 \%\right.$ CI $\left.0.89-1.2 ; p_{\text {add }}=0.7\right)$ and $\mathrm{OR}_{\text {add }} 1.1$ (95\% CI $\left.0.90-1.2 ; p_{\text {add }}=0.4\right)$, respectively (Table 1$)$. Metaanalyses for rs1535435 and rs9494266 combining data from the present study with data from the Diabetes Genetics Initiative (DGI) [5] and from the Wellcome Trust Case Control Consortium (WTCCC) [10] GWA studies did not support an association with type 2 diabetes: $\mathrm{OR}_{\text {add }} 0.97$ $(95 \%$ CI $0.89-1.06 ; p=0.6)$ and $\mathrm{OR}_{\text {add }} 0.98$ (95\% CI $0.91-$ $1.06 ; p=0.6$ ), respectively (Fig. 1a,b).

Furthermore, rs1535435 and rs9494266 were investigated for an association with type 2 diabetes-related quantitative traits in the population-based Inter99 sample involving 6,038 treatment-naive middle-aged individuals (ESM Table 2). The rs1535435 A-allele was nominally associated with increased serum insulin and C-peptide concentrations at $120 \mathrm{~min}\left(p_{\text {add }}=0.01\right.$ and $p_{\text {add }}=0.004$, respectively). Increased AUC for serum insulin, plasma glucose and C-peptide concentrations was also observed $\left(p_{\text {add }}<0.05, p_{\text {add }}=0.04\right.$ and $p_{\text {add }}=0.03$, respectively $)$. The rs9494266 A-allele was nominally associated with increased serum insulin and C-peptide concentrations at $120 \mathrm{~min}$ ( $p_{\text {add }}=0.01$ and $p_{\text {add }}=0.004$, respectively). Increased AUC for plasma glucose was observed for the rs9494266 A-allele $\left(p_{\text {add }}=0.01\right)$.

Registered data on plasma glucose (ADDITION, capillary blood glucose), BMI, total cholesterol and HDLcholesterol were available for 17,521 participants (from Inter99, ADDITION and Steno study samples). Participants homozygous for the rs1535435 and rs9494266 A-alleles 
Table 1 Association study of type 2 diabetes in 4,104 type 2 diabetes patients and 5,050 glucose-tolerant control participants

\begin{tabular}{|c|c|c|c|c|c|c|c|c|c|}
\hline \multirow[t]{2}{*}{ SNP } & \multirow[t]{2}{*}{$\begin{array}{l}\text { Allele } \\
\text { (minor/major) }\end{array}$} & \multirow[t]{2}{*}{$\begin{array}{l}\text { MAF } \\
(\%)\end{array}$} & \multirow[t]{2}{*}{ Genotype } & \multicolumn{2}{|l|}{$\begin{array}{l}\text { Genotype } \\
\text { distribution }\end{array}$} & \multirow{2}{*}{$\begin{array}{l}\text { Allele } \\
\text { association } \\
\text { OR }(95 \% \mathrm{CI})^{\mathrm{a}}\end{array}$} & \multirow{2}{*}{$\begin{array}{l}\text { Additive } \\
\text { model OR } \\
(95 \% \mathrm{CI})^{\mathrm{b}}\end{array}$} & \multirow{2}{*}{$\begin{array}{l}\text { Dominant } \\
\text { model OR } \\
(95 \% \mathrm{CI})^{\mathrm{b}}\end{array}$} & \multirow{2}{*}{$\begin{array}{l}\text { Recessive } \\
\text { model OR } \\
(95 \% \mathrm{CI})^{\mathrm{b}}\end{array}$} \\
\hline & & & & $\begin{array}{l}\text { NGT, } \\
n(\%)\end{array}$ & $\begin{array}{l}\mathrm{T} 2 \mathrm{D} \\
n(\%)\end{array}$ & & & & \\
\hline \multirow[t]{3}{*}{ rs 1535435} & \multirow[t]{3}{*}{$\mathrm{A} / \mathrm{G}$} & \multirow[t]{3}{*}{8.4} & GG & $4,019(84)$ & $3,228(84)$ & \multirow{3}{*}{$\begin{array}{l}1.0(0.9-1.1) \\
p=0.8\end{array}$} & \multirow{3}{*}{$\begin{array}{l}1.0(0.9-1.2) \\
p=0.7\end{array}$} & \multirow{3}{*}{$\begin{array}{l}1.0(0.9-1.2) \\
p=0.6\end{array}$} & \multirow{3}{*}{$\begin{array}{l}0.9(0.4-1.9) \\
p=0.8\end{array}$} \\
\hline & & & GA & $731(15)$ & $594(15)$ & & & & \\
\hline & & & AA & $40(1)$ & $25(1)$ & & & & \\
\hline \multirow[t]{3}{*}{ rs9494266 } & \multirow[t]{3}{*}{$\mathrm{A} / \mathrm{G}$} & \multirow[t]{3}{*}{8.5} & GG & $3,971(84)$ & $3,222(84)$ & $(0.9-1.1)$ & $1.1(0.9-1.2)$ & $1.1(0.9-1.3)$ & $1.2(0.6-2.6)$ \\
\hline & & & GA & $729(15)$ & $598(15)$ & \multirow[t]{2}{*}{$p=1.0$} & \multirow[t]{2}{*}{$p=0.4$} & \multirow[t]{2}{*}{$p=0.5$} & \multirow[t]{2}{*}{$p=0.6$} \\
\hline & & & AA & $35(1)$ & $26(1)$ & & & & \\
\hline
\end{tabular}

MAF, minor allele frequency; NGT, normal glucose tolerance; T2D, type 2 diabetes

${ }^{\mathrm{a}}$ Not adjusted for age, BMI or sex

${ }^{\mathrm{b}}$ Adjusted for age, BMI and sex

had reduced BMI compared with carriers of the G-allele $\left[27.8 \pm 5.0 \mathrm{vs} 26.7 \pm 4.4 \mathrm{~kg} / \mathrm{m}^{2}\left(p_{\mathrm{rec}}=0.03\right)\right.$ and $27.8 \pm 5.0 \mathrm{vs}$ $26.9 \pm 4.5 \mathrm{~kg} / \mathrm{m}^{2}\left(p_{\text {rec }}<0.05\right)$, respectively] (ESM Table 2). Analyses were adjusted for age, BMI, sex and diabetes status, since the complete cohort also includes individuals with type 2 diabetes.

a

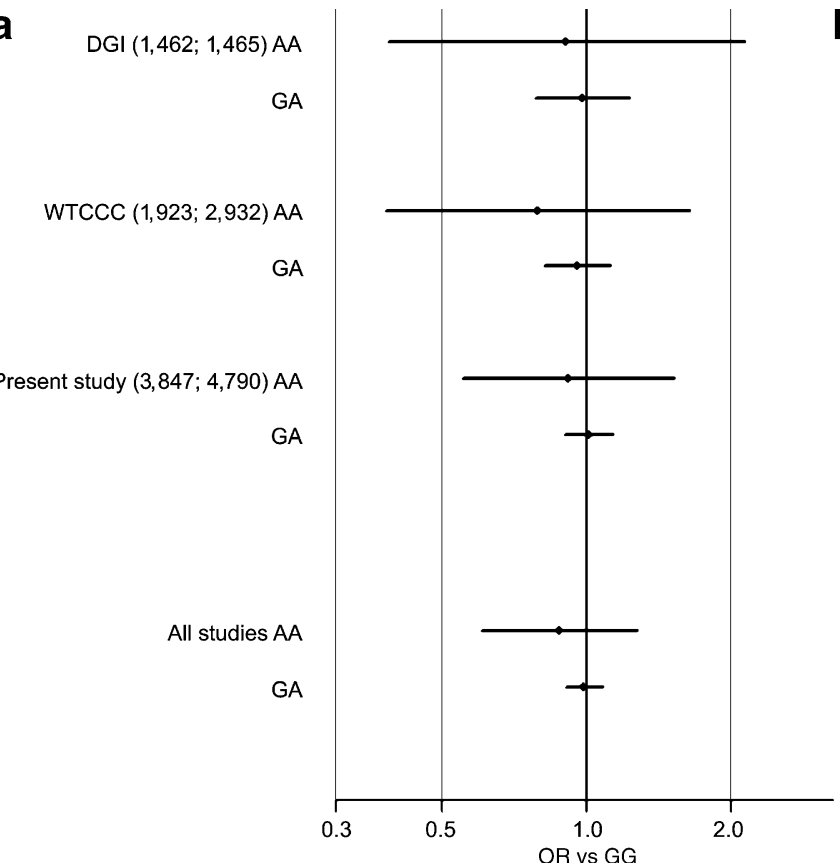

Fig. 1 Meta-analysis for a rs9494266 and b rs1535435. Values are ORs with $95 \%$ CI. For each study, the vertical tick represents the OR for the given genotype and the horizontal line represents its $95 \%$ CI. Imputed data for rs1535435 was available from the WTCCC [10], but

\section{Discussion}

The AHI1 locus is located on chromosome 6q23.3, which has shown suggestive linkage to type 2 diabetes and related metabolic traits [18-22]. In a recent GWA study for type 2 diabetes, two single-nucleotide polymorphism (SNPs;

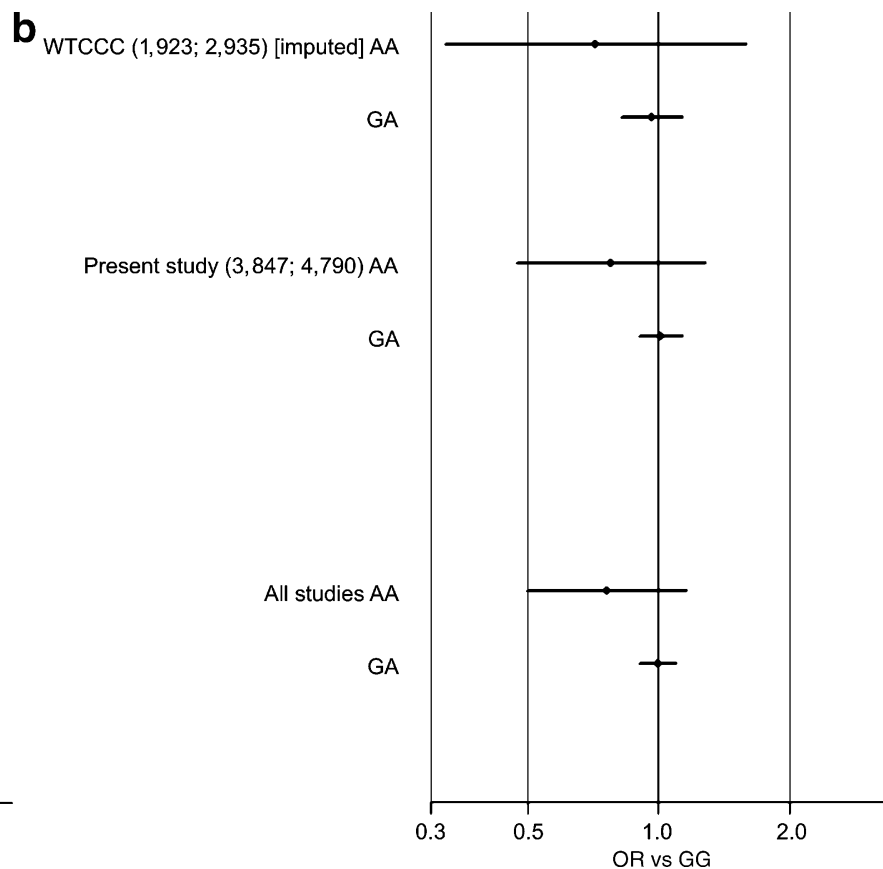

not from the DGI [5] study. Numbers within parentheses represents the number of type 2 diabetes patients and glucose-tolerant control participants in the individual studies 
rs1535435 and rs9494266) in the AHII locus were associated with type 2 diabetes and were internally replicated with significant $p$ values in an independent large cohort [11]. This is the only one of 12 recent GWAs for type 2 diabetes that has shown GWA $\left(p<2.3 \times 10^{-7}\right)$ at this locus. Based on the strong association data and data describing suggestive linkage to type 2 diabetes and related metabolic traits adjacent (centromeric) to this locus, we decided to investigate the putative association with type 2 diabetes and its related quantitative metabolic traits for the recently described polymorphisms associated with type 2 diabetes in the AHII locus in a large independent sample of well-characterised Danish individuals.

We were not able to confirm the previously reported association with type 2 diabetes for rs 1535435 and rs9494266, either in our case-control sample comprising $>9,000$ individuals ( $p=0.7$ and $p=0.4$ ), or in a meta-analysis comprising $>16,300$ individuals drawn from our study and from the publicly available DGI and WTCCC GWAs $[5,10]$ ( $p=0.6$ and $p=0.6$, respectively). Neither were we able to show significant association with investigated type 2 diabetes-related quantitative metabolic traits in the large population-based Inter99 cohort $(n=6038)$ or when analysing all participants $(n=17521$, recruited from the Inter99 cohort, the ADDITION and Steno study samples).

Our results are in contrast to those from Salonen et al. [11], who showed that rs1535435 and rs9494266 in the AHII locus were associated with type 2 diabetes. The discrepancy between the results in that study and ours might suggest that the results in the original study were due to chance. That initial report showed surprisingly high OR (2.3), possibly representing a 'jackpot' effect due to heterogeneity of the GWA samples (derived from four different white populations), differences in study design and the low power in the sample used in the genome-wide approach. It should be appreciated that $p<2.3 \times 10^{-7}$ used in the original study to declare genome-wide significance only represents borderline significance in the context of GWAs [37]. Other explanations for the discrepant results could be that the two polymorphisms are in high linkage disequilibrium with a causative variant in the original publication investigating Finns, Ashkenazi Jews and UK, German and French individuals; but this was not the case in our study, which investigated Danes. In this context, it is important to note that we limited our search to just these two SNPs and could therefore have missed a potential causative variant in the AHII locus that is not in linkage disequilibrium with these two SNPs in our population. Despite the strong internal replication in a large well-powered sample of different ethnic origin (French), no association with type 2 diabetes was seen for rs9494266 (or imputed data for rs15353435) in the recent DGI and WTCCC GWA studies
$[5,10]$, which cover $\sim 77 \%\left(r^{2}>0.8\right)$ of the common genetic variation at this locus. Internal replication efforts are often biased (errors in phenotyping or genotyping and population stratification) and might be an explanation for the results in the original publication, indicating the need for independent validation. In this respect, our study is an independent statistically well-powered association study in $>17,000$ individuals, looking for a possible role of two previously genome-wide associated SNPs in the AHII locus in the development of type 2 diabetes.

In conclusion, we have shown that the two previously associated SNPs (rs1535435 and rs9494266) in AHII locus are not associated with type 2 diabetes or related quantitative metabolic traits.

Acknowledgements The authors wish to thank A. Forman, I.-L. Wantzin and M. Stendal for technical assistance and G. Lademann for secretarial support. The study was supported by grants from the European Union (EUGENE2, grant no. LSHM-CT-2004-512013), the FOOD Study Group/the Danish Ministry of Food, Agriculture and Fisheries and the Ministry of Family and Consumer Affairs (grant no. 2101-05-0044).

Duality of interest K. Borch-Johnsen holds stock in Novo Nordisk and has received lecture fees from pharmaceutical companies. The remaining authors declare that there is no duality of interest associated with this manuscript.

\section{References}

1. Zimmet P, Alberti KGMM, Shaw J (2001) Global and societal implications of the diabetes epidemic. Nature 414:782-787

2. International Diabetes Federation (2006) Diabetes Atlas. Available from www.eatlas.idf.org, accessed 09 July 2006

3. Hirschhorn JN, Daly MJ (2005) Genome-wide association studies for common diseases and complex traits. Nat Rev Genet 6:95-108

4. Carlson CS, Eberle MA, Kruglyak L, Nickerson DA (2004) Mapping complex disease loci in whole-genome association studies. Nature 429:446-452

5. Saxena R, Voight BF, Lyssenko V et al (2007) Genome-wide association analysis identifies loci for Type 2 Diabetes and triglyceride levels. Science 316:1331-1336

6. Scott LJ, Mohlke KL, Bonnycastle LL et al (2007) A genomewide association study of Type 2 Diabetes in Finns detects multiple susceptibility variants. Science 316:1341-1345

7. Sladek R, Rocheleau G, Rung J et al (2007) A genome-wide association study identifies novel risk loci for type 2 diabetes. Nature 445:881-885

8. Steinthorsdottir V, Thorleifsson G, Reynisdottir I et al (2007) A variant in CDKAL1 influences insulin response and risk of type 2 diabetes. Nat Genet 39:770-775

9. The Wellcome Trust Case Control Consortium (2007) Genomewide association study of 14,000 cases of seven common diseases and 3,000 shared controls. Nature 447:661-678

10. Zeggini E, Weedon MN, Lindgren CM et al (2007) Replication of genome-wide association signals in UK samples reveals risk loci for Type 2 Diabetes. Science 316:1336-1341 
11. Salonen J, Uimari P, Aalto J-M et al (2007) Type 2 diabetes whole-genome association study in four populations: the DiaGen consortium. Am J Hum Genet 81:338-345

12. Florez JC, Manning AK, Dupuis J et al (2007) A 100 K genomewide association scan for Diabetes and related traits in the Framingham Heart Study: replication and integration with other genome-wide datasets. Diabetes 56:3063-3074

13. Hanson RL, Bogardus C, Duggan D et al (2007) A search for variants associated with young-onset Type 2 Diabetes in American Indians in a $100 \mathrm{~K}$ genotyping array. Diabetes 56:3045-3052

14. Hayes MG, Pluzhnikov A, Miyake K et al (2007) Identification of Type 2 Diabetes genes in Mexican Americans through genomewide association studies. Diabetes 56:3033-3044

15. Rampersaud E, Damcott CM, Fu M et al (2007) Identification of novel candidate genes for Type 2 Diabetes from a genome-wide association scan in the Old Order Amish: evidence for replication from diabetes-related quantitative traits and from independent populations. Diabetes 56:3053-3062

16. Gudmundsson J, Sulem P, Steinthorsdottir V et al (2007) Two variants on chromosome 17 confer prostate cancer risk, and the one in TCF2 protects against type 2 diabetes. Nat Genet 39:977-983

17. Ioannidis JPA (2007) Non-replication and inconsistency in the genome-wide association setting. Hum Hered 64:203-213

18. Xiang K, Wang Y, Zheng T et al (2004) Genome-wide search for Type 2 Diabetes/impaired glucose homeostasis susceptibility genes in the Chinese: significant linkage to chromosome 6q21q23 and chromosome 1q21-q24. Diabetes 53:228-234

19. Silander K, Scott LJ, Valle TT et al (2004) A large set of Finnish affected sibling pair families with Type 2 Diabetes suggests susceptibility loci on chromosomes 6, 11, and 14. Diabetes 53:821-829

20. Shtir C, Nagakawa IS, Duren WL et al (2007) Subsets of Finns with high HDL to total cholesterol ratio show evidence for linkage to Type 2 Diabetes on chromosome 6q. Hum Hered 63:17-25

21. Ghosh S, Watanabe RM, Valle TT et al (2000) The Finland-United States investigation of non-insulin-dependent diabetes mellitus genetics (FUSION) study. I. An autosomal genome scan for genes that predispose to type 2 diabetes. Am J Hum Genet 67:1174-1185

22. Duggirala R, Blangero J, Almasy L et al (2001) A major locus for fasting insulin concentrations and insulin resistance on chromosome 6q with strong pleiotropic effects on obesity-related phenotypes in nondiabetic Mexican Americans. Am J Hum Genet 68:1149-1164

23. Ferland RJ, Eyaid W, Collura RV et al (2004) Abnormal cerebellar development and axonal decussation due to mutations in AHI1 in Joubert syndrome. Nat Genet 36:1008-1013

24. Ingason A, Sigmundsson T, Steinberg S et al (2007) Support for involvement of the AHI1 locus in schizophrenia. Eur J Hum Genet 15:988-991
25. Levi A, Kohn Y, Kanyas K et al (2005) Fine mapping of a schizophrenia susceptibility locus at chromosome 6q23: increased evidence for linkage and reduced linkage interval. Eur J Hum Genet 13:763-771

26. Lerer B, Segman RH, Hamdan A et al (2003) Genome scan of Arab Israeli families maps a schizophrenia susceptibility gene to chromosome 6q23 and supports a locus at chromosome 10q24. Mol Psychiatry 8:488-498

27. Dixon-Salazar T, Silhavy JL, Marsh SE et al (2004) Mutations in the AHI1 gene, encoding jouberin, cause Joubert syndrome with cortical polymicrogyria. Am J Hum Genet 75(6):979-987

28. Li D, Roberts R (2001) Human genome and diseases: WD-repeat proteins: structure characteristics, biological function, and their involvement in human diseases. Cell Mol Life Sci 58:2085-2097

29. Mayer B (2001) SH3 domains: complexity in moderation. J Cell Sci 114:1253-1263

30. Jørgensen T, Borch-Johnsen K, Thomsen TF, Ibsen H, Glumer C, Pisinger C (2003) A randomized non-pharmacological intervention study for prevention of ischaemic heart disease: baseline results Inter99. Eur J Cardiovasc Prevent Rehab 10:377-386

31. Clausen J, Borch-Johnsen K, Ibsen H et al (1996) Insulin sensitivity index, acute insulin response, and glucose effectiveness in a population-based sample of 380 young healthy Caucasians. Analysis of the impact of gender, body fat, physical fitness, and life-style factors. J Clin Invest 98:1195-1209

32. Lauritzen T, Griffin S, Borch-Johnsen K, Wareham NJ, Wolffenbuttel BH, Rutten G (2000) The ADDITION study: proposed trial of the cost-effectiveness of an intensive multifactorial intervention on morbidity and mortality among people with Type 2 diabetes detected by screening. Int J Obes Relat Metab Disord 24:S6-S11

33. Alberti KGMM, Zimmet P (1999) Definition, diagnosis and classification of diabetes mellitus and its complications; Part 1: diagnosis and classification of diabetes mellitus. World Health Organization, Geneva

34. Hansen T, Drivsholm T, Urhammer SA et al (2007) The BIGTT Test: a novel test for simultaneous measurement of pancreatic beta-cell function, insulin sensitivity, and glucose tolerance. Diabetes Care 30:257-262

35. Purcell S, Cherny SS, Sham PC (2003) Genetic Power Calculator: design of linkage and association genetic mapping studies of complex traits. Bioinformatics 19:149-150

36. Grarup N, Rose CS, Andersson EA et al (2007) Studies of association of variants near the HHEX, CDKN2A/B, and IGF2BP2 genes with Type 2 diabetes and impaired insulin release in 10,705 Danish subjects: validation and extension of genomewide association studies. Diabetes 56:3105-3111

37. Risch N, Merikangas K (1996) The future of genetic studies of complex human diseases. Science 273:1516-1517 